\title{
Outcomes in medical admissions with hyponatraemia in Ghana - a single-centre study
}

\author{
Elliot Koranteng Tannor', Emmanuel Owusu Akumiah², Betty R Norman³ \\ 'Renal Unit, Department of Medicine, Komfo Anokye Teaching Hospital, Kumasi, Ghana; ${ }^{2}$ Research and Development Unit, Komfo \\ Anokye Teaching Hospital, Kumasi, Ghana; ' ${ }^{D}$ epartment of Medicine, Kwame Nkrumah University of Science and Technology, \\ Kumasi, Ghana.
}

\section{ABSTRACT}

Introduction: Hyponatraemia is the most common electrolyte abnormality in hospitalized patients and is associated with poor prognosis and high mortality. There is a paucity of data on hyponatraemia in Ghana. We set out to describe the prevalence of this condition, its associations and the outcomes in terms of in-hospital mortality and length of hospital stay.

Methods: We conducted a retrospective study of all admissions from October 2017 to April 2018 on the medical ward at the Komfo Anokye Teaching Hospital (KATH). Demographic information, medical diagnoses as well as clinical and laboratory data were documented. Means ( \pm standard deviation) were recorded for normally distributed data, whereas non-normally distributed data were recorded as medians [interquartile range (IQR)]. Chi-squared and Fisher's exact tests were used to test categorical variables. ANOVA and Kruskal-Wallis tests were used for the analysis of hyponatraemia severity; a $p$ value of $<0.05$ was considered statistically significant.

Results: Within the study period, 406 patients with hyponatraemia were identified in 1477 medical admissions, a prevalence of $27.6 \%$. Their mean age was $51.5 \pm 19.0$ years. There were 217 males (53.5\%). The mean serum sodium was $128.7 \pm 6.5 \mathrm{mmol} / \mathrm{L}$. Two hundred and forty (59\%) had mild hyponatraemia, 106 (26\%) had moderate hyponatraemia and 60 (15\%) had severe hyponatraemia. The most common associated medical conditions were infections (26\%), chronic liver disease (17\%), hyperglycaemia (17\%), chronic kidney disease (16\%) and chronic heart failure (8\%). In-hospital mortality was $31.8 \%$ and varied with the severity of the hyponatremia. The median length of hospital stay was 7 days (IQR 4-10 days) and did not vary with the severity of hyponatraemia. Mortality was associated with serum sodium concentration $(p=0.007)$ and lower levels of consciousness (Glasgow Coma Scale, GCS, $\leq 13)$ at presentation $(p<0.001)$.

Conclusions: Hyponatraemia is common in medical admissions in Ghana, and is mostly associated with infections, and chronic liver, kidney and heart diseases. It is associated with high in-hospital mortality, especially when hyponatraemia is more severe or accompanied by relatively low GCS scores.

Keywords: hyponatraemia; mortality; Ghana.

\section{INTRODUCTION}

Hyponatraemia, defined by a serum sodium concentration of less than $135 \mathrm{mmol} / \mathrm{L}$, is the most common electrolyte abnormality in hospitalized patients $[1,2]$. It is present in approximately 15\% of hospital admissions [3], is associated with increased morbidity and mortality, and is often poorly recognised and managed. Normally, serum sodium concentration is tightly controlled by mechanisms including antidiuretic hormone $(\mathrm{ADH})$ and the thirst response. Abnormalities in serum sodium concentration indicate a disruption in the body's control systems for water $[2,4]$.

There are many causes that may contribute to hyponatraemia. They include medications, malignancies, infections, cardiac failure, liver failure and renal disease. These 
conditions are mostly described as causing the syndrome of inappropriate anti-diuretic hormone (SIADH) secretion, where $\mathrm{ADH}$ is acting when the serum sodium concentration and/or serum osmolality is low. Non-osmotic states such as pain, anxiety and nausea can also cause ADH secretion and hyponatraemia [5]. Acute hyponatraemia has also been described in long-distance runners due to water overload [6]. The condition may present with symptoms ranging from headache, nausea, vomiting and fatigue to seizures and coma.

In hospitalized patients, a serum sodium concentration of less than $125 \mathrm{mmol} / \mathrm{L}$ has been associated with poor prognosis. Mortality rates associated with hyponatraemia range from $0.9-29.6 \%$ of hospital admissions with the highest among patients in the intensive care units $[7,8]$. It is not certain whether hyponatraemia contributes to the higher mortality or is just a marker of the poor prognosis in chronic conditions [9].

In Ghana, there has been no study on the prevalence and outcomes of hyponatraemia in hospitalized patients. There have been case studies describing the condition in patients with hypothyroidism [I0] and bronchial carcinoma [I I]. In this study, we describe the prevalence of hyponatraemia in a tertiary institution in Ghana, and describe the causes and outcomes among patients in terms of in-hospital mortality and length of hospital stay.

\section{METHODS}

We conducted a retrospective study of adult ( $>18$ years) medical admissions at the Komfo Anokye Teaching Hospital (KATH) with serum sodium concentration less than $135 \mathrm{mmol} / \mathrm{L}$. The study period was from | October 2017 to 30 April 2018. KATH is a 1200-bed hospital in the Ashanti region, which receives referrals from about half of Ghana's 27 million population in the northern half of the country. The hospital has twelve clinical directorates including the Internal Medicine directorate with a bed capacity of 203.

Two patients among the medical admissions were not considered for inclusion as they did not have serum sodium measurements. Demographic data including age and sex were recorded. Presenting symptoms such as nausea, vomiting, oedema, seizures and pain were recorded if documented in the clinical notes. Level of consciousness graded using the Glasgow Coma Scale (GCS) was also recorded. Low level of consciousness was defined as GCS of $\leq 13$. Serum sodium concentration was categorised as mild when between $130-134$ mmol/L, moderate between
125-129 mmol/L and severe when less than $125 \mathrm{mmol} / \mathrm{L}$. Critical hyponatraemia was defined as serum sodium concentration of less than $120 \mathrm{mmol} / \mathrm{L}$. The medical diagnoses were also recorded and the most likely contributory causes of the hyponatraemia were identified. Outcome variables documented were the length of hospital stay and in-hospital mortality.

Means and standard deviation were used to describe normally distributed variables and medians and interquartile range for variables not normally distributed. Figures and tables were used to describe data where appropriate. The chi-squared and Fisher's exact tests were used for categorical variables. Student's t test and the Wilcoxon sign rank test were used for continuous variables. ANOVA and Kruskal-Wallis tests were used to test for differences related to the severity of hyponatremia. Multiple logistic regression was then used to identify predictors of mortality. A $P$ value of $<0.05$ was considered statistically significant.

Ethical approval was granted before the start of the study from the Committee on Human Research, Publications and Ethics, School of Medical Sciences, Kwame Nkrumah University of Science and Technology.

\section{RESULTS}

The study identified 406 patients with hyponatraemia in 1479 medical admissions within the study period, yielding a prevalence of $27.6 \%$. The mean age was $51.5 \pm 19.0$ years. There were 217 males (53.5\%). The mean serum sodium concentration was $128.7 \pm 6.5 \mathrm{mmol} / \mathrm{L}$ (Table I).

The most common medical conditions associated with hyponatraemia were infections ( 105 patients, 26\%), chronic liver disease $(69,17 \%)$, diabetes mellitus $(68,17 \%)$ and chronic kidney disease (66, 16\%) (Figure I). When hyponatraemia was classified by volume status, 17\% were hypovolaemic, 41\% were euvolaemic and 43\% were hypervolaemic.

In-hospital mortality was 32\%. Of the patients who died, mortality varied significantly with the diagnosis ( $p=0.012$ ), with the highest rate among patients with malignancies (46\%), cranial pathologies (44\%), chronic liver disease (4l\%), chronic kidney disease (38\%) and infections (35\%) (Figure I).

In-hospital mortality also varied with the severity of hyponatraemia. Mild hyponatraemia had an associated mortality rate of $21 \%$, moderate hyponatraemia $45 \%$ and severe hyponatraemia 52\% ( $p<0.001)$. Mortality did not vary with volume status. 
Table I. Demographics and clinical data of patients with hyponatraemia.

\begin{tabular}{|c|c|c|c|c|c|}
\hline Variable & $\begin{array}{c}\text { Total } \\
n=406\end{array}$ & $\begin{array}{c}\text { Mild } \\
n=240\end{array}$ & $\begin{array}{c}\text { Moderate } \\
\mathrm{n}=106\end{array}$ & $\begin{array}{l}\text { Severe } \\
n=60\end{array}$ & $P$ value \\
\hline Male n (\%) & $217(53.5)$ & $123(51.3)$ & $59(55.7)$ & $35(58.3)$ & 0.535 \\
\hline Age (years) & $51.5 \pm 19.0$ & $52.6 \pm 19.7$ & $47.9 \pm 18.3$ & $53.5 \pm 16.0$ & 0.068 \\
\hline Pain n (\%) & $264(65.0)$ & $161(67.1)$ & $72(67.9)$ & $3 \mid(5 \mid .7)$ & 0.062 \\
\hline Nausea n (\%) & $112(27.6)$ & $51(21.3)$ & $38(35.9)$ & $23(38.3)$ & 0.002 \\
\hline Oedema n (\%) & $142(35.0)$ & $36(31.3)$ & $16(28.6)$ & $12(4 \mid .4)$ & 0.283 \\
\hline Seizures n (\%) & $38(9.4)$ & $20(8.3)$ & $9(8.4)$ & $9(15.0)$ & 0.267 \\
\hline $\mathrm{GCS} \leq 13 \mathrm{n}(\%)$ & $76(18.7)$ & $36(15.0)$ & $19(17.9)$ & $21(35.0)$ & 0.002 \\
\hline Systolic BP (mmHg) & $134.5 \pm 36.8$ & $132.6 \pm 34.6$ & $132.0 \pm 36.6$ & $146.4 \pm 43.7$ & 0.024 \\
\hline Diastolic BP (mmHg) & $82.3 \pm 22.3$ & $81.6 \pm 21.1$ & $81.1 \pm 24.3$ & $87.3 \pm 23.3$ & 0.170 \\
\hline Serum sodium (mmol/L) & $128.7 \pm 6.5$ & $132.3 \pm 1.4$ & $127.3 \pm 1.6$ & $116.4 \pm 7.9$ & $<0.001$ \\
\hline Random blood glucose (mmol/L) & $8.7(6.9-11.3)$ & $8.8(7.1-11.6)$ & $8.2(6.8-11.0)$ & $9.1(7.2-10.8)$ & 0.528 \\
\hline Haemoglobin $(\mathrm{g} / \mathrm{dL})$ & $10.2 \pm 3.1$ & $10.5 \pm 3.1$ & $9.5 \pm 2.8$ & $9.9 \pm 3.4$ & 0.013 \\
\hline Serum albumin $(g / L)$ & $31.6 \pm 16.5$ & $31.4 \pm 9.1$ & $28.6 \pm 7.8$ & $29.4 \pm 12.0$ & 0.026 \\
\hline Serum urea $(\mathrm{mmol} / \mathrm{L})$ & $6.9(3.9-15.6)$ & $5.5(3.4-\mid 1.1)$ & $7.7(4.9-24.5)$ & I $1.5(5.5-29.0)$ & 0.0001 \\
\hline Serum creatinine $(\mu \mathrm{mol} / \mathrm{L})$ & $59(61-232.5)$ & $86(60-153)$ & $96(6 \mid-349)$ & | 48 (75.5-486.5) & 0.002 \\
\hline In-hospital mortality n (\%) & $129(31.8)$ & $50(20.8)$ & $48(45.3)$ & $3 \mid(5 \mid .7)$ & $<0.001$ \\
\hline Length of hospital stay (days) & $7(4-10)$ & $7(4-10.5)$ & $6.5(3-10)$ & $6.5(3-11)$ & 0.639 \\
\hline
\end{tabular}

Continuous variables reported as mean \pm standard deviation or median (interquartile range); GCS, Glasgow Coma Scale.

The median duration of hospital stay was 7 days (IQR 4- 10 days) and did not vary significantly with the severity of hyponatraemia.

Among patients with GCS $\leq 13,67 \%$ died $(p<0.001)$. The mean serum sodium for those who died was lower, 126.0 $\pm 8.5 \mathrm{mmol} / \mathrm{L}$ versus $129.9 \pm 4.8 \mathrm{mmol} / \mathrm{L}(p<0.00 \mathrm{l})$. The in-hospital mortality of those with critical hyponatraemia was $70 \%$.

Multiple logistic regression revealed that serum sodium concentration $(p=0.007)$ and GCS $\leq 13(p<0.001)$ were predictors of mortality (Table 3 ).

\section{DISCUSSION}

This is the first study of hyponatremia in Ghana describing the prevalence, causes and outcomes of the condition. We report a hyponatraemia prevalence of $27.6 \%$ in our hospitalized medical cases, similar to prevalences in other in patients with infections and chronic oedematous conditions such as liver, heart and kidney disease, and had a high in-hospital mortality. Mortality was associated with the severity of hyponatraemia and decreased level of consciousness.

There were more males with hyponatraemia, which contrasts with other reports in which females were at higher risk as a result of their lower body weight and total body water [13]. Higher proportions of males have also been reported in hospitalized patients, especially among those with chronic heart failure, chronic liver disease and malignancies [14]. Our higher proportion of males may be due to the frequency of chronic liver disease, alcoholism and CKD in our study.

Infections were the most common cause of hyponatremia in our cohort. Infections such as pneumonia have been reported as a cause of hyponatraemia in $28 \%$ of cases in another study [15]. Hyponatraemia in the setting of infections may be due to renal hypoperfusion, leading to 


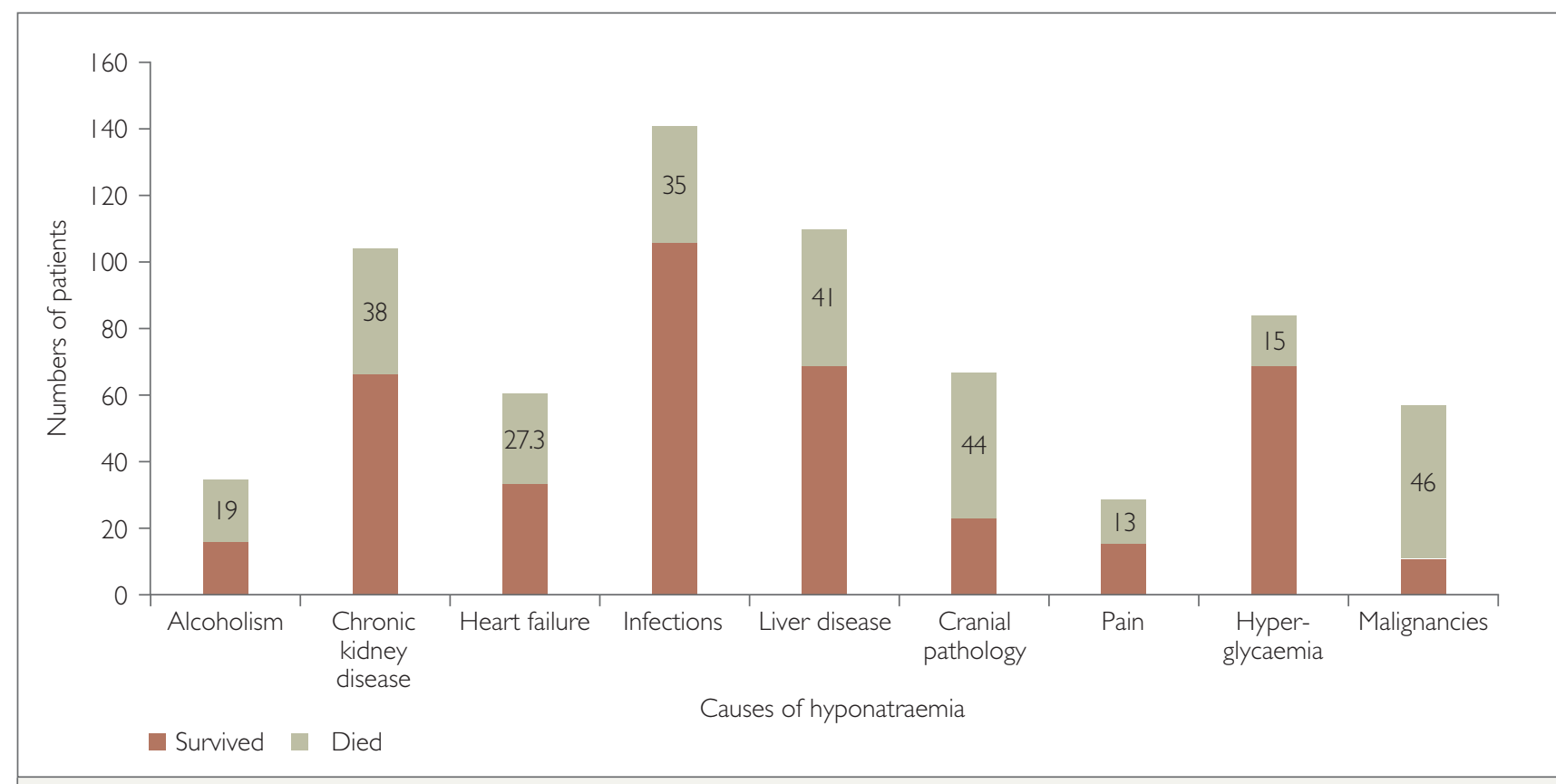

Figure I. Causes of hyponatraemia and associated mortality in medical admissions.

Table 2. Determinants of mortality among patients with hyponatraemia.

\begin{tabular}{|c|c|c|c|}
\hline & $\begin{array}{c}\text { Died } \\
(n=129)\end{array}$ & $\begin{array}{l}\text { Survived (n } \\
\quad=277)\end{array}$ & $P$ value \\
\hline Male n (\%) & 7I (33) & $146(67)$ & 0.661 \\
\hline Age (years) & $51.2 \pm 19.7$ & $51.7 \pm 18.7$ & 0.807 \\
\hline Pain n (\%) & $75(28.4)$ & I89 (7I.6) & 0.047 \\
\hline Nausea n (\%) & $43(38.4)$ & $69(61.6)$ & 0.077 \\
\hline Dehydration n (\%) & $28(29.8)$ & $66(70.2)$ & 0.637 \\
\hline Oedema n (\%) & $38(26.8)$ & $104(73.2)$ & 0.112 \\
\hline Seizures n (\%) & $17(44.7)$ & $21(55.3)$ & 0.071 \\
\hline GCS $\leq 13$ & $51(67.1)$ & $25(32.9)$ & $<0.001$ \\
\hline Systolic BP (mmHg & $|34.8 \pm 36|$. & $134.3 \pm 37.2$ & 0.890 \\
\hline Diastolic BP (mmHg) & $82.3 \pm 22.3$ & $82.4 \pm 22.6$ & 0.890 \\
\hline $\begin{array}{l}\text { Serum sodium } \\
(\mathrm{mmol} / \mathrm{L})\end{array}$ & $126.0 \pm 8.5$ & $129.9 \pm 4.8$ & $<0.001$ \\
\hline $\begin{array}{l}\text { Critical } \\
\text { hyponatraemia n (\%) }\end{array}$ & $19(70.4)$ & $8(29.6)$ & $<0.001$ \\
\hline $\begin{array}{l}\text { Random blood } \\
\text { glucose }\end{array}$ & $\begin{array}{c}8.6 \\
(7.1-11.1)\end{array}$ & $\begin{array}{c}8.7 \\
(6.8-\mid 1.5)\end{array}$ & 0.981 \\
\hline Haemoglobin (g/dL) & $9.7 \pm 3.1$ & $10.4 \pm 3.1$ & 0.027 \\
\hline Serum albumin $(g / L)$ & $28.4 \pm 10.2$ & $31.3 \pm 8.7$ & 0.006 \\
\hline $\begin{array}{l}\text { Serum urea } \\
(\mathrm{mmol} / \mathrm{L})\end{array}$ & $\begin{array}{c}8.3 \\
(4.8-20.7)\end{array}$ & $\begin{array}{c}6.2 \\
(3.5-12.7)\end{array}$ & 0.005 \\
\hline $\begin{array}{l}\text { Serum creatinine } \\
(\mu \mathrm{mol} / \mathrm{L})\end{array}$ & $\begin{array}{c}103 \\
(7 \mid-342)\end{array}$ & $89(59-176)$ & 0.026 \\
\hline $\begin{array}{l}\text { Length of hospital } \\
\text { stay (days) }\end{array}$ & $4(2-9)$ & $7(4-11)$ & $<0.001$ \\
\hline
\end{tabular}

Continuous variables reported as mean \pm standard deviation or median
Table 3. Logistic regression for variables associated with mortality in patients with hyponatraemia.

\begin{tabular}{|lcc|}
\hline & $\begin{array}{c}\text { Odds ratio (95\% } \\
\text { confidence interval) }\end{array}$ & P value \\
\hline $\begin{array}{l}\text { Serum albumin } \\
\text { concentration }\end{array}$ & $0.97(0.95-1.00)$ & 0.124 \\
Haemoglobin & $0.93(0.85-1.02)$ & 0.114 \\
Critical hyponatraemia & $1.13(0.25-5.16)$ & 0.867 \\
Serum sodium & $0.91(0.87-0.98)$ & 0.009 \\
concentration & $7.7(4.09-14.50)$ & $<0.001$ \\
GCS $\leq 13$ & $0.94(0.55-1.61)$ & 0.829 \\
Pain &
\end{tabular}

Critical hyponatraemia refers to serum sodium less than $120 \mathrm{mmol} / \mathrm{L} ; \mathrm{GCS}$, Glasgow Coma Scale.

$\mathrm{ADH}$ release and water retention [2,4]. Infections identified in our cohort included pneumonia, encephalitis, urinary tract infection, sepsis, and HIV with its related infections. Hyponatremia occurs in around $30 \%$ of HIV-infected patients [16]. Infections are more common in low- and lower-middle-income countries and this may account for the prominence of infections as a cause of hyponatraemia in our cohort.

Hypervolaemic conditions, such as chronic liver disease (CLD), were identified as a significant cause of hyponatraemia in our cohort. CLD causes hyponatraemia in $30 \%$ of cases. The pathophysiology includes renal hypoperfusion, secondary hyperaldosteronism, ADH release and hypoalbuminemia [17]. Hyponatraemia is associated 
with a poor prognosis in patients with CLD [18] or other oedematous conditions such as heart failure [19].

Heart failure accounted for $8.1 \%$ of patients with hyponatraemia in our cohort, which is less than reported in many other studies [20]. The mechanism is multifactorial but mainly due to arterial under-filling, which leads to neurohormonal stimulation. Medications for heart failure, such as thiazide diuretics, are also known causes of hyponatraemia [20]. Mild hyponatraemia, even without severe cardiac dysfunction, is associated with increased morbidity and mortality $[21]$.

Diabetes mellitus was associated with 17\% of the cases in our cohort. Hyperglycaemia-induced hyponatraemia is well described in the literature [22]. The high serum tonicity leads to movement of water from the intracellular to extracellular fluid compartments and hence results in a decrease in serum sodium concentration [23]. Osmotic diuresis also leads to hypovolaemia, which increases ADH secretion. Moreover, polydipsia contributes to dilutional hyponatraemia [24].

CKD is another cause of hypervolaemic hyponatraemia, with a prevalence of 6\% in non-dialysis CKD patients [25]. CKD accounted for $6 \%$ of our cases. Chronic kidney disease is common in hospital admissions in Ghana and patients often present late, with advanced disease [26]. Hyponatraemia in CKD patients is associated with increased mortality [27].

Mortality occurred in over a third of cases of hyponatraemia in our study. This was higher than in most studies, which report prevalences of 15-27\% [7]. Mortality was highest among patients with malignancies, similar to other studies [28]. Mortality increased significantly with severity of hyponatraemia; this has also been reported in other studies $[14,29]$. Serum sodium predicts mortality as shown in most studies [7, I4,27]. Mortality was significantly higher among those with impaired consciousness. This may be due to their underlying conditions and not necessarily the hyponatraemia $[9,23]$. Many medical conditions have hyponatraemia as a poor prognostic factor for the underlying condition $[10,14,20]$.

In our study, those who died with hyponatraemia had significantly higher median serum urea and creatinine values. Renal impairment worsens the prognosis of most medical conditions [30].

\section{CONCLUSIONS}

Hyponatraemia is common in medical admissions in Ghana, disease, chronic kidney disease and chronic heart failure. There is high in-hospital mortality and this is associated with serum sodium concentration and an impaired level of consciousness.

\section{Acknowledgments}

We thank all the nurses and doctors at the Komfo Anokye Teaching Hospital who helped in the management of the cases recruited for this study. We thank the Department of Internal Medicine for access to the data.

\section{REFERENCES}

I. Kumar S, Berl T. Electrolyte quintet. Sodium. Lancet. 1998; 352:220-228.

2. Adrogué HJ, Madias NE. Hyponatremia. N Engl J Med. 2000; 342:1581-1589.

3. Flear CG, Gill G, Burn J. Hyponatraemia: mechanisms and management. Lancet. 1981; 318:26-31.

4. Soupart A, Decaux G. Therapeutic recommendations for management of severe hyponatremia: current concepts on pathogenesis and prevention of neurologic complications. Clin Nephrol. 1996; 46:149-169.

5. Gill G, Leese G. Hyponatraemia: biochemical and clinical perspectives. Postgrad Med J. 1998; 74:516-523.

6. Speedy DB, Rogers IR, Noakes TD, Wright S, Thompson JM, Campbell R, et al. Exercise-induced hyponatremia in ultradistance triathletes is caused by inappropriate fluid retention. Clin J Sport Med. 2000; 10:272-278.

7. Asadollahi K, Beeching N, Gill G. Hyponatraemia as a risk factor for hospital mortality. J Assoc Physic. 2006; 99:877-880.

8. DeVita M, Gardenswartz M, Konecky A, Zabetakis P. Incidence and etiology of hyponatremia in an intensive care unit. Clin Nephrol. 1990; 34:163-166.

9. Chawla A, Sterns RH, Nigwekar SU, Cappuccio JD. Mortality and serum sodium: do patients die from or with hyponatremia? Clin J Am Soc Nephrol. 201 I; 6(5):960-965.

I0. Akpalu J, Atiase Y, Yorke E, Fiscian H, Kootin-Sanwu C, Akpalu A. Challenges in the management of a patient with myxoedema coma in Ghana: a case report. Ghana Med J. 2017; 51:39-42.

I I. Edwards N. Hyponatraemia and bronchial carcinoma. BMJ. 1963; I (5344): I 547- I 548.

12. Hoorn EJ, Lindemans J, Zietse R. Development of severe hyponatraemia in hospitalized patients: treatment-related risk factors and inadequate management. Nephrol Dial Transplant. 2005; 21:70-76.

13. Upadhyay A, Jaber BL, Madias NE. Incidence and prevalence of hyponatremia. Am J Med. 2006; I 19:S30-S35.

14. Corona G, Giuliani C, Parenti G, Norello D, Verbalis JG, Forti G, et al. Moderate hyponatremia is associated with increased risk of mortality: evidence from a meta-analysis. PLoS ONE. 20। 3; 8:e8045।.

15. Nair V, Niederman MS, Masani N, Fishbane S. Hyponatremia in community-acquired pneumonia. Am J Nephrol. 2007; 27: I 84- 190.

16. Cusano AJ, Thies HL, Siegal FP, Dreisbach AW, Maesaka JK. Hyponatremia in patients with acquired immune deficiency syndrome. J Acquir Immune Defic Syndr. 1990; 3:949-953. 
17. Gianotti RJ, Cardenas A. Hyponatraemia and cirrhosis. Gastroenterol Rep. 2014; 2:21-26.

18. Borroni G, Maggi A, Sangiovanni A, Cazzaniga M, Salerno F. Clinical relevance of hyponatraemia for the hospital outcome of cirrhotic patients. Digest Liver Dis. 2000; 32:605-6I 0.

19. Filippatos TD, Elisaf MS. Hyponatremia in patients with heart failure. World J Cardiol. 20 I3; 5:317.

20. Sica DA. Hyponatremia and heart failure - pathophysiology and implications. Congest Heart Failure. 2005; 1 1:274-277.

21. Gheorghiade M, Abraham WT, Albert NM, Gattis Stough W, Greenberg BH, O'connor CM, et al. Relationship between admission serum sodium concentration and clinical outcomes in patients hospitalized for heart failure: an analysis from the OPTIMIZE-HF registry. Eur Heart J. 2007; 28:980-988.

22. Hillier TA, Abbott RD, Barrett EJ. Hyponatremia: evaluating the correction factor for hyperglycemia. Am J Med. 1999; 106:399-403.

23. Katz MA. Hyperglycemia-induced hyponatremia-calculation of expected serum sodium depression. N Engl J Med. 1973; 289:843-844.

24. Liamis G, Liberopoulos E, Barkas F, Elisaf M. Diabetes mellitus and electrolyte disorders. World J Clin Cases. 2014; 2:488.

25. Han S-W, Tilea A, Gillespie BW, Finkelstein FO, Kiser MA, Eisele G, et al. Serum sodium levels and patient outcomes in an ambulatory clinic-based chronic kidney disease cohort. Am J Nephrol. 20 I5; 41:200-209.

26. Tannor EK, Adusei K, Norman BR. A I0-year retrospective review of renal cases seen in a tertiary hospital in West Africa. Afr J Curr Med Res. 2018; 2.

27. Huang H, Jolly SE, Airy M, Arrigain S, Schold JD, Nally JV, et al. Associations of dysnatremias with mortality in chronic kidney disease. Nephrol Dial Transplant. 2016; 32:1204-1210.

28. Castillo Jj, Vincent M, Justice E. Diagnosis and management of hyponatremia in cancer patients. Oncologist. 20 I 2; 201 I-0400.

29. Wald R, Jaber BL, Price LL, Upadhyay A, Madias NE. Impact of hospital-associated hyponatremia on selected outcomes. Archiv Intern Med. 20 10; 170:294-302.

30. Uchino S, Kellum JA, Bellomo R, Doig GS, Morimatsu H, Morgera S, et al. Acute renal failure in critically ill patients: a multinational, multicenter study. JAMA. 2005; 294:8 13-8 I8. 